\section{Hydralazine induced lupus syndrome with eye disease}

A syndrome resembling systemic lupus erythematosus, characterised by prominent polyarthralgia, arthritis, pleurisy, and a positive antinuclear antibody (ANA) test, is a recognised complication of treatment with hydralazine. It is generally considered a benign condition that resolves without permanent sequelae. ${ }^{1}$

We describe two patients who developed bilateral retinal vasculitis during otherwise typical hydralazine induced lupus syndrome. In one case episcleritis was also present. So far as we are aware this is the first report to associate eye disease with the drug induced lupus syndrome.

\section{Case 1}

A 63 year old woman with essential hypertension presented with a 10 month history of symmetrical hand, wrist, and shoulder arthralgia, blurred vision, malaise, and weight loss. She had taken hydralazine $150 \mathrm{mg}$ day for three years. Examination showed tender but otherwise normal joints; her blood pressure was $115 / 80 \mathrm{~mm} \mathrm{Hg}$. Corrected visual acuities were $6 / 18$ on each side. There was a right sided nodular episcleritis; both vitreous bodies showed mild inflammatory cell infiltration; and both retinas had widespread dot haemorrhages and macular oedema. The results of investigations included: haemoglobin concentration $10 \cdot 2 \mathrm{~g} / \mathrm{dl}$ (normal red cell indices); leucocyte and platelet counts normal; plasma viscosity $1.92 \mathrm{cP}$ (normal range $1.5-1.72 \mathrm{cP}$ ); serum ANA test positive (1/1280) with homogeneous immunofluorescence staining; DNA binding negative; urea, serum complement $(\mathrm{C} 3, \mathrm{C} 4)$, and immunoglobulin concentrations within normal limits. Chest $x$ ray films and joint radiographs were normal. Fluorescein angiography showed arteriolar attenuation with scattered areas of capillary dilatation and leakage in both fundi. Changes at the right macula were consistent with a small branch vein occlusion; elsewhere abnormalities showed focal capillary damage most appreciable in the peripheral fundi. Tissue typing and acetylator state were not assessed.

Her arthralgia, episcleritis, and malaise resolved within four weeks of stopping hydralazine. Ten months later her ANA test remained positive $(1 / 320)$, visual acuities were unaltered, and no new retinal lesions had appeared.

\section{Case 2}

A 53 year old woman with essential hypertension presented with a three month history of symmetrical hand, wrist, and knee arthralgia, general malaise, and weight loss. She had taken hydralazine $150 \mathrm{mg} /$ day for two years. Examination showed normal joints; blood pressure was $125 / 85 \mathrm{~mm} \mathrm{Hg}$. Visual acuities were $6 / 12$ in each eye unaided. Both retinas showed widespread retinal pigment epithelial changes with pigment clumping and also pronounced retinal capillary tortuosity around the prepapillary plexuses. The results of investigations included: haemoglobin concentration $10.9 \mathrm{~g} / \mathrm{dl}$ (normal indices); leucocyte and platelet counts normal; viscosity $1.81 \mathrm{cP}$ serum ANA test positive (1/320) with homogeneous immunofluorescence staining; DNA binding negative; urea, serum complement, and immunoglobulin concentrations normal. Chest $x$ ray and joint radiographs were normal. Tissue typing and acetylator state were not assessed.

Her arthralgia and malaise resolved within three weeks of stopping hydralazine. After six months' follow up her ANA remained positive $(1 / 160)$ and her eyes were unchanged.

\section{Comment}

With the possible exception of the macular branch vein occlusion in case 1 , the retinal changes observed in these patients are not explicable in terms of hypertensive retinopathy alone. ${ }^{2}$ Both patients had raised plasma viscosity, but this was not to the level usually associated with hyperviscosity syndrome and the changes observed are atypical of slow flow retinopathy. ${ }^{2}$ Such abnormalities, however, although non-specific, are fully compatible with the retinal microvascular disturbance described in patients with systemic lupus erythematosus. ${ }^{23}$

Features of both patients' illnesses which are characteristic of hydralazine induced lupus include: prominent polyarthralgia; weight loss; positive ANA test with negative DNA binding; normocomplementaemia; prompt recovery on discontinuing hydralazine and subsequent prolonged ANA positivity. ${ }^{1}$ Although drug induced lupus is usually characterised by limited organ disease and a less severe clinical course than idiopathic systemic lupus erythematosus, ${ }^{1}$ the occasional development of rapidly progressive glomerulonephritis ${ }^{4}$ and vasculitis ${ }^{5}$ has recently been emphasised. The present report suggests that ocular disease is a further potentially serious com- plication of this syndrome. The frequent coexistence of hypertensive retinopathy in patients selected for treatment with hydralazine may well result in underdiagnosis.

We thank the Arthritis and Rheumatism Council for financial support.

1 Harmon CE, Portanova JP. Drug-induced lupus: clinical and serological studies. Clinics in Rheumatic Diseases 1982;8:121-35.

2 Sanders MD. Retinal vasculitis: a review. I Roy Soc Med 1979;72:908-14.

Bishko $F$. Retinopathy in systemic lupus erythematosus-a case report and review of the literature. Arthritis Rheum 1972:15:57-63.

4 Bjorck S, Westberg G, Svalander C, Mulec H. Rapidly progressive glomerulonephritis after hydralazine. Lancet 1982 ;ii :42.

Lancet 1982;ii:348.

(Accepted 4 December 1984)

University Nepartment of Medicine, Bristol Royal Infirmary, Bristol BS2 8HW

MICHAEL DOHERTY, MA, MRCP, senior registrar in rheumatology

Royal National Hospital for Rheumatic Diseases, Bath BA1 1RL

PETER J MADDISON, MD, MRCP, consultant rheumatologist

Bristol Eye Hospital, Bristol BS1 2LY

RODNEY H B GREY, FRCS, consultant ophthalmic surgeon

Correspondence to: $\operatorname{Dr} M$ Doherty, City Hospital, Hucknall Road, Nottingham NG5 $1 \mathrm{~PB}$.

\section{Onycholysis associated with cytotoxic drugs}

Onycholysis is associated with conditions such as psoriasis and hyperthyroidism and with ingestion of drugs, notably tetracycline and captopril. ${ }^{1}$ Only one case has been reported in which onycholysis was attributed to cytotoxic drugs: onycholysis developed after treatment with doxorubicin and was associated with appreciable epidermolysis of the feet and hands. ${ }^{2}$ We report three cases of onycholysis that occurred during cytotoxic treatment without any manifestation of skin toxicity.

\section{Case reports}

Case 1-A 78 year old man presented in October 1983 with generalised lymphadenopathy and hypercalcaemia (calcium concentration $3 \cdot 2 \mathrm{mmol} / \mathrm{l}$ $(13 \mathrm{mg} / 100 \mathrm{ml})$ corrected) and normal nails. Histological examination showed a $\mathrm{T}$ cell non-Hodgkin's lymphoma. The hypercalcaemia was treated with intravenous mithramycin, and he began chemotherapy comprising intravenous cyclophosphamide $(650 \mathrm{mg})$, doxorubicin $(35 \mathrm{mg})$, etoposide $(160 \mathrm{mg})$, bleomycin $(30 \mathrm{mg})$, and vincristine $(2 \mathrm{mg})$ every three weeks. After five cycles almost complete onycholysis of both great toes had occurred, and this progressed to total nail loss with further chemotherapy. No other drugs were being taken. Thyroid function tests gave normal results, and nail scrapings for fungi and hyphae were negative. Serum zinc concentration was $11 \mu \mathrm{mol} / 1(72 \mu \mathrm{g} / 100 \mathrm{ml})$ and zinc clearance $4.5 \mu \mathrm{mol} / 1$ $(294 \mu \mathrm{g} / \mathrm{l})$ (normal ranges $12-18 \mu \mathrm{mol} / 1(78-118 \mu \mathrm{g} / 100 \mathrm{ml})$ and $4 \cdot 6-10 \cdot 5 \mu \mathrm{mol} /$ $1(301-693 \mu \mathrm{g} / \mathrm{l})$ respectively). Creatinine clearance was $80 \mathrm{ml} / \mathrm{min}$. By February 1984 he was in complete remission and chemotherapy was therefore stopped. His nails recovered fully. In June relapse occurred and the same combination chemotherapy was restarted. After three cycles onycholysis recurred.

Case 2-A 47 year old clerk with normal nails, lymphadenopathy, and abdominal mass due to diffuse histiocytic lymphoma presented in December 1983. Combination chemotherapy with intravenous cyclophosphamide $(730 \mathrm{mg})$, doxorubicin $(40 \mathrm{mg})$, etoposide $(194 \mathrm{mg})$, and vincristine $(2 \mathrm{mg})$, intramuscular bleomycin $(30 \mathrm{mg})$, and oral prednisolone $(100 \mathrm{mg}$ for five days) every three weeks was started in February 1984. By the seventh cycle the nails of both great toes were lost and early onycholysis had developed in all finger nails. Nail scrapings for fungi and hyphae yielded negative results. Results of thyroid function tests were normal. Serum zinc concentration was $8 \mu \mathrm{mol} / 1(52 \mu \mathrm{g} / 100 \mathrm{ml})$, zinc clearance $2.0 \mu \mathrm{mol} / \mathrm{l}$ $(131 \mu \mathrm{g} / \mathrm{l})$, and creatinine clearance $88 \mathrm{ml} / \mathrm{min}$. She had not been receiving any other treatment. After chemotherapy was stopped in August the nails began to grow.

Case 3-A 58 year old housewife with breast adenocarcinoma began chemotherapy in January 1984. Her nails were normal. She received antihypertensive treatment with propranolol and bendrofluazide throughout the period of chemotherapy. Chemotherapy comprised intravenous vincristine $(2 \mathrm{mg})$ and doxorubicin $(45 \mathrm{mg})$ and oral prednisolone $(40 \mathrm{mg}$ daily for five days) every three weeks. Complete onycholysis of both great toes occurred after seven cycles. Results of thyroid function tests were normal, 